\title{
Macrophage Phenotypes and Their Modulation in Atherosclerosis
}

\author{
Federica De Paoli; Bart Staels; Giulia Chinetti-Gbaguidi
}

\begin{abstract}
Atherosclerosis is the result of a chronic inflammatory response in the arterial wall related to uptake of low-density lipoprotein by macrophages and their subsequent transformation in foam cells. Monocyte-derived macrophages are the principal mediators of tissue homeostasis and repair, response to pathogens and inflammation. However, macrophages are a homogeneous cell population presenting a continuum phenotypic spectrum with, at the extremes, the classically Th-1 polarized M1 and alternatively Th-2 polarized M2 macrophage phenotypes, which have been well described. Moreover, M2 macrophages also present several subtypes often termed M2a, b, c and d, each of them expressing specific markers and exhibiting specialized properties. Macrophage plasticity is mirrored also in the atherosclerotic lesions, where different stimuli can influence the phenotype giving rise to a complex system of subpopulations, such as Mox, Mhem, M(Hb) and M4 macrophages. An abundant literature has described the potential modulators of the reciprocal skewing between pro-inflammatory M1 and anti-inflammatory M2 macrophages including lesion stage and localization, miRNA, transcription factors such as PPARY, KLF4 and NR4A family members, high-density lipoproteins and plaque lipid content, pathways such as the rapamycin-mTOR1 pathway, molecules such as thioredoxin-1, infection by helminths and irradiation. We hope to provide an overview of the macrophage phenotype complexity in cardiovascular diseases, particularly atherosclerosis. (Circ J 2014; 78: 1775-1781)
\end{abstract}

Key Words: Atherosclerosis; Macrophage phenotypes; Modulators

A therosclerosis is a chronic inflammatory disease affecting blood vessels, in which the arterial wall thickens because of the formation of an atheromatous plaque. The early stages of atherogenesis are characterized by infiltration of monocytes in the subendothelium and their differentiation into macrophages, the orchestrating cells of this disease. Macrophages clear the excess modified lipoproteins that accumulate in the neointima and as a consequence, the macrophages become engorged with lipids and can no longer emigrate from the plaque, contributing to the failure of inflammation resolution and consequent instauration of a complicated atherosclerotic lesion. ${ }^{1}$ Macrophages are present in different regions of the plaque: next to the necrotic core or in the plaque shoulder; next to blood vessels or calcium deposits in more rigid and calcified zones. Thus macrophages, which are plastic cells, are exposed to different environmental stimuli that modulate their activation and polarization (Table). Even though the process of differentiation of monocytes into macrophages is irreversible, macrophage polarization seems to be reversible. $^{2}$

\section{Macrophage Polarization and Plasticity}

Bacterial products such as lipopolysaccharide (LPS) as well as inflammatory cytokines such as interferon- $\gamma($ IFN $-\gamma)$ and tumor necrosis factor- $\alpha$ (TNF- $\alpha$ ), prone macrophages to a classical activation (M1) state. Principal markers of M1 activation are interleukin (IL)-1 $\beta$, TNF- $\alpha$, IL-6, IL-12, IL-23, CXCL9, CXCL10 and CXCL11. These M1 macrophages are characterized by high production of nitric oxide (NO) and reactive oxygen intermediates, and participate in the resistance against intracellular parasites and tumor development. The M1-activated macrophages are named to mirror the fact that they are in the cascade of the Th1 polarized responses. ${ }^{3}$ Th 2 cytokines are not simple inhibitors of this classical activation, but directly participate in the induction of a distinct macrophage phenotype: the alternative-activated M2 macrophage..$^{4,5} \mathrm{M} 2$ macrophages are mainly functional in tissue remodeling, angiogenesis and tumor progression; they are also involved in immunoregulation and allergic reactions. They are typically IL-10 high and IL-12 low. ${ }^{3,6}$

To account for the complexity of macrophage phenotype, the M1/M2 spectrum needed to be extended. Thus, according to the stimulus they receive, alternative M2 macrophages can be classified into at least 4 distinct phenotypes. The M2a phenotype where "a" stands for "alternative", is induced by IL-4 and IL-13 and M2 macrophages highly express the mannose receptor (MR/CD206), the decoy receptor IL-1RII and IL-1

Received June 3, 2014; accepted June 4, 2014; released online July 7, 2014

Université Lille 2, Lille; Inserm Lille, Lille; Institut Pasteur de Lille, Lille; and European Genomic Institute for Diabetes (EGID), Lille, France

Mailing address: Bart Staels, Inserm UR 1011, Institut Pasteur de Lille, 1, rue du Professeur Calmette, BP 245, Lille 59019, France. E-mail: bart.staels@ pasteur-lille.fr

ISSN-1346-9843 doi:10.1253/circj.CJ-14-0621

All rights are reserved to the Japanese Circulation Society. For permissions, please e-mail: cj@j-circ.or.jp 


\begin{tabular}{|c|c|c|c|c|c|}
\hline Phenotype & $\begin{array}{l}\text { Polarization } \\
\text { signal }\end{array}$ & $\begin{array}{l}\text { Markers and } \\
\text { related genes }\end{array}$ & $\begin{array}{l}\text { Cyto/chemokine } \\
\text { production, enzymes, } \\
\text { other secreted factors }\end{array}$ & $\begin{array}{l}\text { Functions and } \\
\text { properties }\end{array}$ & $\begin{array}{l}\text { Presence in } \\
\text { atherosclerotic } \\
\text { lesions }\end{array}$ \\
\hline M1 & IFNY, LPS, TNF $a$ & $\begin{array}{l}\text { IL-1 } \beta \text {, TNF } a, \text { IL-6, IL-12, } \\
\text { IL-23, CXCL9, CXCL10, } \\
\text { CXCL11, Arg-2 (M) }\end{array}$ & $\begin{array}{c}\text { iNOS, ROI, IL-12 high, } \\
\text { IL-10'low, IL-23, IL-6, } \\
\text { TNFa }\end{array}$ & $\begin{array}{l}\text { Th1 immunological response, } \\
\text { tumor resistance }\end{array}$ & $\mathrm{M}, \mathrm{H}$ \\
\hline $\mathrm{M} 2 \mathrm{a}$ & $\begin{array}{l}\text { Th-2 cytokines: } \\
\text { IL-4 and IL-13 }\end{array}$ & $\begin{array}{c}\text { MR }(\mathrm{H}), \text { IL1Ra }(\mathrm{H}) \\
\operatorname{Arg}-1(\mathrm{M}), \mathrm{FIZZ1}(\mathrm{M}) \\
\mathrm{Ym} 1 / 2(\mathrm{M})\end{array}$ & $\begin{array}{c}\text { IL-10, TGF } \beta, \text { CCL22, } \\
\text { CCL17 }\end{array}$ & $\begin{array}{l}\text { Tissue remodeling, } \\
\text { endocytosis }\end{array}$ & $\mathrm{M}, \mathrm{H}$ \\
\hline M2b & IC + LPS $/ I L-1 \beta$ & IL-10high, IL-12low & $\begin{array}{l}\text { IL-10 } 10^{\text {high }}, \text { IL-12low, } \\
\text { TNF } a, \text { IL-6 }\end{array}$ & Immunoregulation & $\mathrm{M}, \mathrm{H}$ \\
\hline M2c & $\begin{array}{l}\text { IL-10, TGF } \beta \text {, } \\
\text { glucocorticoids }\end{array}$ & $\mathrm{MR}(\mathrm{H}), \operatorname{Arg}-1(\mathrm{M})$ & IL-10, TGF $\beta$, PTX3 & $\begin{array}{l}\text { merTK-dependent } \\
\text { efferocytosis }\end{array}$ & $\mathrm{M}, \mathrm{H}$ \\
\hline M2d & $\mathrm{TLR}+\mathrm{A}_{2} \mathrm{R}$ agonists & TNF $a^{\text {low, }}$ IL-12 $2^{\text {low }}$ & VEGF, IL-10, iNOS & $\begin{array}{l}\text { Pro-angiogenic, } \\
\text { tumor promotion }\end{array}$ & $M$ \\
\hline M4 & CXCL4 & MMP7, S100A8, MR & MMP12, IL-6, TNF $a$ & $\begin{array}{l}\text { Weakly phagocytic, minimal } \\
\text { foam cell formation }\end{array}$ & $\mathrm{H}$ \\
\hline Mox & oxLDL & $\begin{array}{l}\text { HMOX-1, Srxn1, } \\
\text { Txnrd1, Nrf2 }\end{array}$ & IL-10, IL-1 $\beta$ & $\begin{array}{l}\text { Pro-atherogenic, } \\
\text { weakly phagocytotic }\end{array}$ & $M$ \\
\hline HA-mac & $\begin{array}{l}\text { Hemoglobin/ } \\
\text { haptoglobin }\end{array}$ & CD163 high, HLA-DR ${ }^{\text {low }}$ & HMOX-1 & $\begin{array}{c}\text { Anti-atherogenic, } \\
\text { hemoglobin clearance }\end{array}$ & $\mathrm{H}$ \\
\hline$M(\mathrm{Hb})$ & $\begin{array}{l}\text { Hemoglobin/ } \\
\text { haptoglobin }\end{array}$ & CD163, MR & LXRa, ABCA1, ABCG1 & $\begin{array}{l}\text { Hemoglobin clearance, } \\
\text { strong cholesterol efflux }\end{array}$ & $\mathrm{H}$ \\
\hline Mhem & Heme & CD163, ATF1 & $\mathrm{LXR} \beta$ & $\begin{array}{l}\text { Anti-atherogenic, } \\
\text { erythrophagocytosis }\end{array}$ & $\mathrm{M}, \mathrm{H}$ \\
\hline
\end{tabular}

Arg, arginase; FIZZ1, found in inflammatory zone 1; H, human; HMOX, heme oxygenase; IFN, interferon; IL, interleukin; iNOS, inducible nitric oxide synthase; LPS, lipopolysaccharide; LXR, liver X receptor; M, murine; MerTK, Mer receptor kinase; MMP, matrix metalloproteinase; Nrf2, redox-regulated transcription factor 2; oxLDL, oxidized low-density lipoprotein; PTX3, pentraxin-3; ROI, reactive oxygen intermediates; TGF, transforming growth factor; TNF, tumor necrosis factor; VEGF, vascular endothelial growth factor.

receptor antagonist. M2b macrophages are induced by exposure to immune complexes and Toll-like receptor (TLR) agonists or IL-1 receptor ligands; they show the typical M2 characteristics, but also produce pro-inflammatory cytokines such as TNF- $\alpha$, IL- $1 \beta$ and IL- $6 .{ }^{7}$ The highly efferocytotic M2c macrophages are induced by IL-10 and glucocorticoids, express pentraxin- 3 and high amounts of TGF- $\beta$ and IL-10. Moreover, they display high levels of the Mer receptor kinase (MerTK), which is crucial for their intense efferocytotic activity. ${ }^{7,8} \mathrm{Fi}$ nally, M2d macrophages are induced by TLR agonists that stimulate the adenosine $\mathrm{A}_{2 \mathrm{~A}}$ receptor. Adenosine signaling suppresses TNF- $\alpha$, IL- 1 and IFN- $\gamma$ expression and confers a pro-angiogenic profile to macrophages, inducing the expression of vascular endothelial growth factor (VEGF) and IL$10 .^{9,10}$

Moreover, growth factors such as granulocyte-macrophage colony stimulating factor (GM-CSF) or macrophage colony stimulating factor (M-CSF) lead to functional macrophage phenotypes similar to the M1 and M2 phenotypes. ${ }^{11,12}$

The properties of alternative macrophages are well conserved among species, although the signature markers of alternative activation differ between murine and human macrophages. In particular, the transcription factor, found in inflammatory zone 1 (FIZZ1), the association of the chitinase 3-like 3 lectin (also referred as Ym1), arginase-1 (Arg1) as well as general arginine metabolism are specific for murine M2 macrophages. ${ }^{13}$ Moreover, the M2d subtype does not express Ym1, FIZZ1 or MR. ${ }^{13}$ Finally, a new macrophage phenotype differing from the M1-M2 phenotype has been described and called M4 because it is induced by CXCL4 (formerly known as platelet factor 4). ${ }^{14}$

\section{Macrophage Phenotypes in Atherosclerotic Lesions}

\section{Human Lesions}

Human atherosclerotic lesions have a highly heterogeneous phenotype and environment. Many factors in the microenvironment can modulate the macrophage phenotype: not only cytokines, but also bioactive lipids (cholesterol crystals, oxidized lipoproteins, fatty acids) ${ }^{15}$ and immune complexes. The presence of pro-inflammatory macrophages was demonstrated several decades ago, whereas the identification of alternative M2 macrophages in atherosclerotic plaques is more recent. ${ }^{16}$ M2 macrophages, positively stained for CD68 and MR, were first identified far from the lipid core, in more stable zones of the lesion. $\mathrm{CD}^{+} 8^{+} \mathrm{MR}^{+}$macrophages are present in areas rich in IL-4 and are filled with less and smaller lipid droplets than $\mathrm{CD}^{+}{ }^{+} \mathrm{MR}^{-}$macrophages. ${ }^{17}$

Boyle et al identified a novel macrophage subset located in hemorrhagic zones of plaques, called HA-mac, defined by high levels of CD163, but low levels of human leukocyte antigen-DR. ${ }^{18}$ These macrophages are mainly anti-atherogenic and involved in hemoglobin clearance and reduction of oxidative stress. Closely related to HA-mac are Mhem macrophages, with their high potential for ingesting erythrocytes, and displaying a strong heme-dependent phosphorylation and activation of the activating transcription factor 1 . This transcription factor induces heme oxygenase (HMOX-1) expression and the liver $\mathrm{X}$ receptor $\alpha(\mathrm{LXR} \alpha) / \mathrm{ABCA} 1 /$ apolipoprotein-E (ApoE) cascade that has a protective function against foam cell formation. ${ }^{19}$ Moreover, hemoglobin/haptoglobin ingestion by macrophages gives rise to $\mathrm{M}(\mathrm{Hb})$ macrophages with high surface expression of the M2 markers MR and CD163. ${ }^{20}$ Neovascularization is frequently found in atherosclerotic plaques and leads to erythrocyte infiltration with a consequent accumula- 
tion of iron in the lesion. $\mathrm{CD}^{+} 8^{+} \mathrm{MR}^{+}$alternative macrophages strongly colocalize with iron deposits, further suggesting a role for these M2 macrophages in iron handling and recycling. ${ }^{21}$

An M4 macrophage population has been identified in human atherosclerotic plaques, based on the expression of the matrix metalloproteinase (MMP) 7 and the calcium-binding protein S100A8. ${ }^{22}$ M4 macrophages express MMP12, the MR but also some pro-inflammatory cytokines such as IL-6 and TNF- $\alpha$. As a trade mark of CXCL4 polarization, M4 macrophages do not express the hemoglobin-haptoglobin scavenger receptor CD163. ${ }^{23}$

\section{Murine Lesions}

Besides the M1, M2 and heme/hemoglobin-related macrophages that have been identified in both humans and mice, a distinct phenotype specific for mouse plaques is constituted by Mox macrophages. ${ }^{24}$ Mox macrophages are induced by the accumulation of oxidized phospholipids in the lesions. This subpopulation highly expresses HMOX-1, by a mechanism involving the redox-regulated transcription factor $2 .{ }^{24}$ FACS analysis performed on established aortic lesions from $\mathrm{LDLR}^{-/-}$ mice showed that M1 macrophages represent approximately $40 \%$, with Mox $30 \%$ and M2 20\% of the total number of macrophages. ${ }^{24}$

Although the in vitro conditions to generate the different subtypes of macrophages are well defined, the in vivo situation is more complex. Several subpopulations of macrophages coexist simultaneously in atherosclerotic lesions and show specific characteristics according to the zone where they are located (Table). However, the mechanisms controlling the generation of the different subtypes, together with their specific functions, are poorly understood.

\section{Macrophage Phenotypes and the Progression of Atherosclerosis}

Given the complexity of the macrophage phenotypes and their ability to exert opposing pro- and anti-inflammatory properties, it is speculated that their phenotypic modulation plays a role in the development of atherosclerosis.

Macrophages infiltrating atherosclerotic lesions in young (20-week-old) ApoE knockout (KO) mice fed a chow diet show the alternative-Arg $1^{+} \mathrm{M} 2$ phenotype, while during disease progression, a switch from the M2 to the M1 phenotype is observed. Interestingly, the cytokine microenvironment changes over time: an increase in the expression of IFN- $\gamma$ at the expense of IL-4 is observed in advanced atherosclerotic lesions, leading to enrichment with pro-inflammatory Arg2+ M1 macrophages during plaque growth. ${ }^{25}$ Moreover ApoE KO mice fed a high-cholesterol diet show after 10 weeks high levels of M-CSF driven alternative-M2 marker expression (selenoprotein-1, stabilin-1 and CD163) that goes in parallel with plaque development. By the way, the GM-CSF-driven M1-related gene proplatelet basic protein (PPBP)) is induced only in very early lesions (6 weeks of diet) and then its expression decreases. These findings mirror the in vivo GM-CSF:M-CSF ratio that changes during the progression of atherosclerotic lesions. ${ }^{26}$

In humans, the content of both M1 and M2 macrophages increase during the progression of atherosclerotic lesions. ${ }^{27}$ Moreover, both phenotypes are more abundant in unstable vs. stable plaques. Interestingly, the different macrophage subtypes are found in different locations in the plaque: M1 macrophages are mainly found in rupture-prone zones, such as the plaque shoulder, whereas there are no dominant phenotypes in the fibrous cap. Surprisingly, M2 macrophages strongly infil- trate the vascular adventitia. ${ }^{27}$ More recently, analysis of the relationship between macrophage phenotype and plaque vulnerability by comparing specimens from symptomatic patients suffering from acute ischemic attack and asymptomatic patients without any symptoms, revealed that M1 macrophages are exclusively found in plaques of symptomatic patients and higher in unstable plaques, whereas M2 macrophages are present in both symptomatic and asymptomatic patients, being higher in stable plaques. ${ }^{28}$

These observations led to the hypothesis that the M1/M2 macrophage ratio, as well as their specific location within the atherosclerotic lesion, can be a determinant of plaque stability.

\section{Modulation of the Macrophage Phenotypes}

Several factors have been found to modulate reciprocal skewing between the pro-inflammatory M1 and the anti-inflammatory M2 macrophage phenotypes.

\section{Modulation by MicroRNAs (miRNAs)}

miRNAs are short non-coding RNAs of approximately 22nt, which have been highly conserved during evolution. ${ }^{29}$ Transcribed by RNA polymerase II as a primary mRNA, they are further processed by Drosha and DGCR8 into a pre-miRNA. Pre-miRNAs are exported from the nucleus to the cytoplasm, processed by Dicer and subsequently loaded onto the RISC complex. ${ }^{30}$ Once in mature form, they bind to target mRNAs, leading to their degradation and/or repression of translation. ${ }^{31}$ miRNAs play pivotal roles in the regulation of macrophage development and functions. ${ }^{32}$ Several miRNA are expressed in human and murine atherosclerotic plaques. ${ }^{33,34}$ Among the best studied miRNAs, miR-155 is highly expressed in macrophages, even though also expressed by a subset of smooth muscle cells in atherosclerotic lesions. ${ }^{35}$ miR-155 is classified as a pro-inflammatory miRNA: its expression is induced by TLR stimulation and it enhances the production of pro-inflammatory cytokines. Moreover, miR-155 is upregulated in M1 macrophages, where it promotes the classical activation phenotype by increasing CCL2 and TNF- $\alpha$ production via inhibition of B-cell lymphoma-6 protein (BCL6) expression. ${ }^{35}$ Deletion of miR-155 in hematopoietic cells reduces advanced atherosclerotic plaque formation. ${ }^{36,37}$ Moreover, miR-155 also contributes to the alteration of macrophage phenotype by reducing the expression of some M2 markers (Arg-1 and Chi313). ${ }^{38}$

By contrast, miR-147, which is also induced by pro-inflammatory stimuli, constrains the inflammatory response of macrophages, being part of a negative feedback loop inhibiting the NF $\kappa$ B pathway. ${ }^{39}$ Together with miR-147, miR-2 $1^{40}$ and the 2 members of the miR-146 family (miR-146a/b) ${ }^{41}$ are inhibitors of $\mathrm{NF} \kappa \mathrm{B}$, reducing pro-inflammatory cytokine production and, concerning miR-21, increasing the expression of the anti-inflammatory cytokine IL-10. ${ }^{40}$

Another 2 miRNAs have been identified as participating in the modulation of the macrophage phenotype: let-7e, which is induced by the LPS-activated-protein kinase Akt1 and represses TLR4 signaling, ${ }^{42}$ and miR125b, which is downregulated by Akt1 and targets the transcription factor IFN regulatory factor 4 , thus inhibiting the alternative activation of macrophages. ${ }^{43}$

\section{Modulation by Transcription Factors}

During the past few years, several studies have outlined the role of nuclear receptors and transcription factors in the modulation of the macrophage phenotype in atherosclerosis (Figure). One of the most important is peroxisome proliferator-activat- 


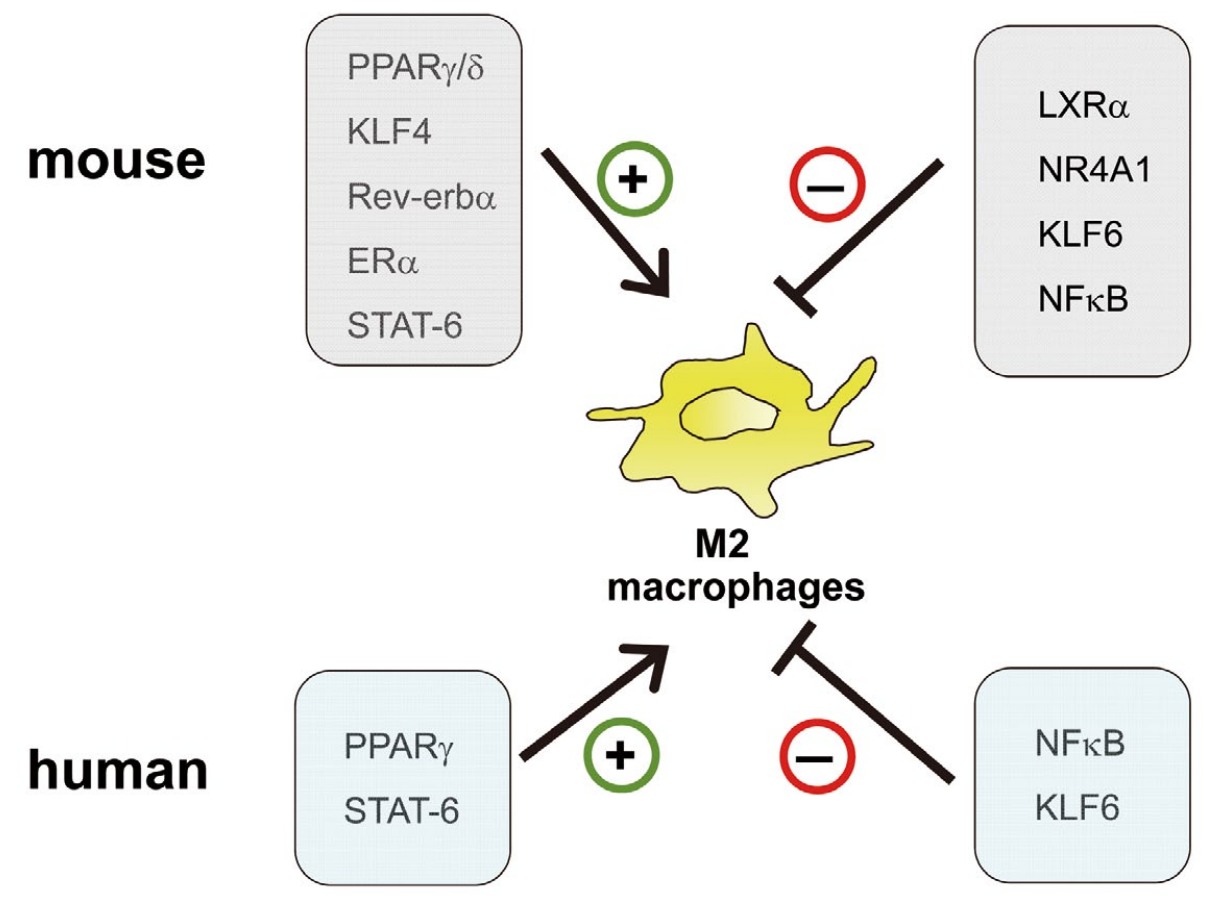

Figure. Transcription factors controlling the M2 macrophage phenotype. The anti-inflammatory alternative-activated M2 macrophage phenotype is finely regulated by several transcription factors. The actors in this regulation differ between mice and humans. PPARY and STAT-6 promote and NFKB and KLF6 repress the M2 phenotype in both species. On the other hand, KLF4, Rev-erba and ER $a$ are specific inducers of the alternative phenotype in murine macrophages, while LXRa and NR4A1 (Nur77) are thought to decrease the M2 activation profile exclusively in mice. ER, estrogen receptor; KLF, Kruppel-like factor; LXR, liver X receptor; $\mathrm{NF}_{k \mathrm{~B}}$, nuclear factor $\kappa \mathrm{B}$; NR, nuclear receptor; PPAR, peroxisome proliferator-activated receptor; Rev-erb, Reverse-erb; STAT, signal transducer and activator of transcription.

ed receptor $\gamma(\operatorname{PPAR} \gamma)$, the expression of which positively correlates with the expression of alternative M2 markers such as MR, AMAC and IL-10, in human carotid plaques. ${ }^{16}$ In vitro, PPAR $\gamma$ primes human alternative polarization only when it is activated at the initial stage of monocyte differentiation. ${ }^{16}$ In mice, PPAR $\gamma$ controls Arg1 expression in concert with PPAR $\delta .{ }^{44}$ By contrast, PPAR $\alpha$ and PPAR $\beta / \delta$ activation do not modulate M2 marker expression in human macrophages. ${ }^{45}$ Different responses are elicited by PPARs in tissues not directly linked with atherosclerosis development. $\operatorname{PPAR} \beta / \delta$, for example, was shown to be necessary for the regulation of the alternative phenotype of murine Kupffer cells and adipose tissue macrophages. ${ }^{46,47}$ PPAR $\gamma$ affects the M1/M2 balance in obese mice by decreasing the number of M1 macrophages and inducing the expression of M2 markers in adipose tissue. ${ }^{48,49}$

Kruppel-like factor (KLF) 4 is essential for alternative polarization in mice, by increasing the expression of Arg1 via the STAT6-signaling pathway and decreasing the expression of pro-inflammatory genes via partial inhibition of NF- $\kappa \mathrm{B}$ transcriptional activity. ${ }^{50}$ More recently, KLF6 was also identified as a transcription factor playing a role in macrophage polarization both in humans and mice, inhibiting the M2 phenotype by suppressing PPAR $\gamma$ expression and promoting the M1 phenotype in concert with $\mathrm{NF} \kappa \mathrm{B} .{ }^{51}$ However, no data are currently available to directly link these 2 members of the KLF family with atherosclerosis.

LXR $\alpha$ indirectly decreases the expression of the M2 mark- er Arg1 in murine macrophages, hence contributing to plaque regression. ${ }^{52}$ In human macrophages, $\mathrm{LXR} \alpha$ is expressed at relatively low levels in IL-4 polarized $\mathrm{CD}^{+} 8^{+} \mathrm{MR}^{+}$macrophages, which show a decreased capacity to handle and efflux excess cholesterol. ${ }^{17}$ Recently, the expression of the nuclear receptor Rev-erb $\alpha$ was demonstrated in human carotid artery atherosclerotic lesions, colocalizing with the pan-macrophage marker CD68. ${ }^{53}$ Rev-erb $\alpha$ elicits anti-atherogenic functions by increasing the expression of several M2 markers (Arg1, MR and $\mathrm{Ym} 1 / 2$ ) and decreasing the mRNA level of the M1 marker, inducible macrophage-type NO synthase (iNOS).

Nuclear receptors of the NR4A family have also been highly investigated for their implication in macrophage polarization in mice, but data for human macrophages are still lacking. Nur77 (also referred to as NR4A1) is more highly expressed in $\mathrm{LyC6C}^{-} \mathrm{CCR} 2^{-} \mathrm{CXCR}^{\mathrm{hi}} \mathrm{CD} 62 \mathrm{~L}^{-}$patrolling or resident monocytes that tend to differentiate into alternative M2 macrophages. ${ }^{54}$ Moreover, Nur77-deficiency in mice leads to a switch toward the pro-inflammatory M1 phenotype with a reduction in IL-12, iNOS and TNF- $\alpha$ expression combined with an increased Arg1 expression..$^{55,56}$ However, these results were recently challenged by a study showing that neither Nur77 nor NOR1 (also known as NR4A3) are main players in macrophage polarization. Transplantation of Nur77- or NOR1-deficient hematopoietic precursors into LDL-R deficient recipient mice did not result in any changes toward the M1 phenotype..$^{57}$

Estrogens exert their biological functions by binding to es- 
trogen receptor $(\mathrm{ER}) \alpha(\mathrm{NR} 3 \mathrm{~A} 1 ; \mathrm{ER} \alpha)$ and $-\beta(\mathrm{NR} 3 \mathrm{~A} 2 ; \mathrm{ER} \beta) .{ }^{58}$ Hematopoietic/myeloid-specific deletion of $\operatorname{ER} \alpha$ gives rise to more severe atherosclerotic lesions in mice. ${ }^{59}$ Expression of $\mathrm{ER} \alpha$ is induced by IL- 4 and is required for the induction of M2 markers such as PPAR $\gamma / \delta$, Ch3I3, TGF- $\beta$, as well as the enzyme transglutaminase 2 (TGM2), while the expression of pro-inflammatory markers IFN- $\gamma$, IL- 6 and IL- $1 \beta$ is downregulated..$^{59}$

\section{Modulation by High-Density Lipoproteins (HDLs)}

HDLs protect against atherosclerosis through a process called reverse cholesterol transport. ${ }^{60}$ In fact, HDLs are good acceptors of cholesterol derived from foam cells. HDLs also transfer cholesteryl esters to triglyceride-rich particles via cholesteryl ester transfer protein to form chylomicron remnants and lowdensity lipoprotein, which are then transported to tissues and catabolized. ${ }^{60}$ Moreover, they have been shown to possess potent anti-inflammatory activities, such as preventing monocyte adhesion to the surface of cultured human umbilical vein endothelial cells. ${ }^{61}$

Given these pleiotropic anti-atherogenic activities, several laboratories have investigated whether HDLs can affect macrophage alternative polarization. Feig et al demonstrated in a murine model of atherosclerosis regression that normalization of HDL content leads to a reduction in the $\mathrm{CD}^{+} 8^{+}$macrophage content of plaques, together with an increase in M2 markers (Arg1, CD163 and FIZZ1). ${ }^{62} \mathrm{HDL}$ regulation of Arg-1 and FIZZ1 occurs through a STAT6-dependent mechanism. ${ }^{63}$ By contrast, HDLs do not induce any change in the expression of alternative polarization markers in human M2 macrophages. ${ }^{64}$

\section{Modulation by Thioredoxin-1 (Trx-1)}

Trx- 1 is a protein secreted by a variety of normal and transformed cells and can be detected in plasma. It plays a critical role in the protection against oxidative stresses. Trx-1 maintains intracellular cysteine residues in the reduced state, and acts upon release as a cytokine. ${ }^{65,66}$ Trx-1 also exerts anti-inflammatory and anti-apoptotic effects and recently its potential role as a modulator of the macrophage phenotype has been investigated. ${ }^{67}$ In vitro experiments showed that Trx- 1 treatment promotes alternative M2 macrophage polarization by inducing the expression of MR and IL-10, and decreasing the production of M1 cytokines, such as TNF- $\alpha$ and MCP1. Consistently, in vivo experiments in transgenic human ApoE2 mice challenged with LPS and treated with Trx-1 showed a shift from the M1 to the M2 phenotype combined with a reduction in atherosclerotic lesions. ${ }^{67}$ Moreover, Trx- 1 colocalizes with MR but not with TNF- $\alpha$ in human atherosclerotic plaques. ${ }^{67} \mathrm{By}$ contrast, the truncated form of thioredoxin, Trx-80, which has pro-inflammatory and atherogenic properties, resulted in attenuation of the M2 phenotype and enhancement of atherosclerosis progression with macrophages exhibiting an M1 state. ${ }^{68}$

\section{Modulation by Rapamycin (RAPA) and mTOR Pathway}

RAPA is a macrocyclic triene antibiotic produced by the actinomycete Streptomyces hygroscopicus,${ }^{69}$ which is commonly used as an immunosuppressor. RAPA inhibits T-cell proliferation $^{70}$ by targeting the mammalian/mechanistic target of RAPA (mTOR) phosphatidylinositol 3'-kinase-like family. ${ }^{71}$ mTOR has been demonstrated to be a critical regulator of monocyte, macrophage and myeloid dendritic cell survival and proliferation. ${ }^{72,73}$

In vitro as well as in vivo, RAPA induces the cell death exclusively of M2 alternative macrophages and not M1 macrophages. ${ }^{74}$ Furthermore, it induces an imbalance between these
2 macrophage phenotypes by increasing the expression of classical activation (CCR7, IL-6, TNF- $\alpha$, IL-1 $\beta$ ) markers in M1 macrophages and by decreasing the expression of M2 markers (IL-10, MR, CCL18 and VEGF) in both M1 and M2 macrophages. ${ }^{74}$ In parallel, bone marrow-derived macrophages derived from mice with a constitutive activation of the mTOR complex (mTORC1) showed a strong defect in M2 marker expression and an exacerbated M1 response to LPS stimulation, because of mTORC1 alteration of Akt signaling independent of PPAR $\gamma$ Activation. ${ }^{75}$ Simultaneously, RAPA treatment rescues the expression of M2 markers. Globally, these data suggest that further investigations are needed to elucidate the role of RAPA and the mTOR pathway in macrophage polarization.

\section{Modulation by Helminth Infection}

A negative correlation between Schistosoma infection and the incidence of cardiovascular diseases has been reported in the past. ${ }^{76}$ Helminths are eukaryotic parasitic worms that induce a Th2 response and alternatively activated macrophages that are crucial for host survival. After S. mansoni infection, a higher hepatic expression of alternative macrophage markers (Ym1/2, FIZZ1 and Mg12) is observed. ${ }^{77}$ The $S$. mansoni-derived soluble egg antigens (SEAs) have been reported as new modulators of the macrophage phenotype in vivo. ${ }^{78}$ Indeed, SEA treatment of $\mathrm{LDLR}^{-1-}$ mice reduced plaque size, as shown by a reduction in lesion cholesterol content, but also to decreased expression of inflammatory markers (MCP1, VCAM1, TNF$\alpha$ ), damping IL-10 production.

\section{Modulation by Irradiation}

Cancer patients undergoing thoracic radiotherapy show an increased incidence of localized atherosclerosis. ${ }^{79,80}$ In fact, irradiation of early stage atherosclerotic plaques accelerates the severity of the lesions, inducing a strong inflammatory response and priming them for rupture. ${ }^{81,82}$ Because older cancer patients treated by thoracic irradiation often have early or advanced atherosclerosis, the effect of irradiation on macrophage polarization has been evaluated.

Local 14-Gy irradiation of pre-existing aortic atherosclerotic lesions in $\mathrm{ApoE}^{-/-}$mice resulted in smaller lesions containing a higher amount of M1 and a decreased number of M2 macrophages. ${ }^{83}$ Besides, irradiation decreased the efferocytotic capacity of M2 macrophages, possibly contributing to the larger number of apoptotic cells in the lesions, creating in a stronger inflammatory environment. This change in plaque cytokine content switches macrophages to the M1 phenotype, which could thus contribute to the increased M1:M2 macrophage ratio in irradiated lesions.

\section{Conclusions}

Monocyte-derived macrophages are the main actors in the development of atherosclerosis, and respond to a multitude of stimuli that modulate the phenotype of the macrophages, according to their capacity to skew reciprocally from the M1 to M2 phenotype. The natural purpose of this plasticity is the necessary adaptation to the lesion environment in an attempt to reach equilibrium between their destructive and/or reparative functions. It is crucial to define the markers, properties and localization for all the different subpopulations of macrophages in order to better define their relative roles. Moreover, the discovery of novel molecules/mechanisms able to modulate the macrophage phenotype will allow the identification of potential therapeutic targets and approaches to treat athero- 
sclerosis and related disorders.

\section{Acknowledgments}

Grants from the Fondation de France, the Fondation pour la Recherche Médicale, and the "European Genomic Institute for Diabetes" (EGID, ANR-10-LABX-46) are acknowledged. B. Staels is a member of the Institut Universitaire de France.

\section{References}

1. Ross R. Atherosclerosis: An inflammatory disease. $N$ Engl J Med 1999; 340: 115-126.

2. Porcheray F, Viaud S, Rimaniol AC, Leone C, Samah B, DereuddreBosquet N, et al. Macrophage activation switching: An asset for the resolution of inflammation. Clin Exp Immunol 2005; 142: 481 -489.

3. Mantovani A, Garlanda C, Locati M. Macrophage diversity and polarization in atherosclerosis: A question of balance. Arterioscler Thromb Vasc Biol 2009; 29: 1419-1423.

4. Gordon S, Martinez FO. Alternative activation of macrophages: Mechanism and functions. Immunity 2010; 32: 593-604.

5. Stein M, Keshav S, Harris N, Gordon S. Interleukin 4 potently enhances murine macrophage mannose receptor activity: A marker of alternative immunologic macrophage activation. J Exp Med 1992; 176: $287-292$.

6. Mantovani A, Sica A, Sozzani S, Allavena P, Vecchi A, Locati M. The chemokine system in diverse forms of macrophage activation and polarization. Trends Immunol 2004; 25: 677-686.

7. Martinez FO, Sica A, Mantovani A, Locati M. Macrophage activation and polarization. Front Biosci 2008; 13: 453-461.

8. Zizzo G, Hilliard BA, Monestier M, Cohen PL. Efficient clearance of early apoptotic cells by human macrophages requires M2c polarization and MerTK induction. J Immunol 2012; 189: 3508-3520.

9. Pinhal-Enfield G, Ramanathan M, Hasko G, Vogel SN, Salzman AL, Boons GJ, et al. An angiogenic switch in macrophages involving synergy between Toll-like receptors 2, 4, 7, and 9 and adenosine A(2A) receptors. Am J Pathol 2003; 163: 711-721.

10. Ferrante CJ, Pinhal-Enfield G, Elson G, Cronstein BN, Hasko G, Outram S, et al. The adenosine-dependent angiogenic switch of macrophages to an M2-like phenotype is independent of interleukin-4 receptor alpha (IL-4Ralpha) signaling. Inflammation 2013; 36: 921-931.

11. Verreck FA, de Boer T, Langenberg DM, Hoeve MA, Kramer M, Vaisberg E, et al. Human IL-23-producing type 1 macrophages promote but IL-10-producing type 2 macrophages subvert immunity to (myco)bacteria. Proc Natl Acad Sci USA 2004; 101: 4560-4565.

12. Waldo SW, Li Y, Buono C, Zhao B, Billings EM, Chang J, et al. Heterogeneity of human macrophages in culture and in atherosclerotic plaques. Am J Pathol 2008; 172: 1112-1126.

13. Martinez FO, Gordon S, Locati M, Mantovani A. Transcriptional profiling of the human monocyte-to-macrophage differentiation and polarization: New molecules and patterns of gene expression. J Immunol 2006; 177: 7303-7311.

14. Gleissner CA, Shaked I, Little KM, Ley K. CXC chemokine ligand 4 induces a unique transcriptome in monocyte-derived macrophages. J Immunol 2010; 184: 4810-4818.

15. Adamson S, Leitinger N. Phenotypic modulation of macrophages in response to plaque lipids. Curr Opin Lipidol 2011; 22: 335-342.

16. Bouhlel MA, Derudas B, Rigamonti E, Dievart R, Brozek J, Haulon $\mathrm{S}$, et al. PPARg activation primes human monocytes into alternative M2 macrophages with anti-inflammatory properties. Cell Metab 2007; 6: $137-143$.

17. Chinetti-Gbaguidi G, Baron M, Bouhlel MA, Vanhoutte J, Copin C, Sebti Y, et al. Human atherosclerotic plaque alternative macrophages display low cholesterol handling but high phagocytosis because of distinct activities of the PPAR $\gamma$ and LXR $\alpha$ pathways. Circ Res 2011; 108: 985-995.

18. Boyle JJ, Harrington HA, Piper E, Elderfield K, Stark J, Landis RC, et al. Coronary intraplaque hemorrhage evokes a novel atheroprotective macrophage phenotype. Am J Pathol 2009; 174: 1097-1108.

19. Boyle JJ, Johns M, Kampfer T, Nguyen AT, Game L, Schaer DJ, et al. Activating transcription factor 1 directs Mhem atheroprotective macrophages through coordinated iron handling and foam cell protection. Circ Res 2012; 110: 20-33.

20. Finn AV, Nakano M, Polavarapu R, Karmali V, Saeed O, Zhao X, et al. Hemoglobin directs macrophage differentiation and prevents foam cell formation in human atherosclerotic plaques. $J$ Am Coll Cardiol 2012; 59: 166-177.

21. Bories G, Colin S, Vanhoutte J, Derudas B, Copin C, Fanchon M, et al. Liver $\mathrm{X}$ receptor (LXR) activation stimulates iron export in human alternative macrophages. Circ Res 2013; 113: 1196-1205.

22. Erbel C, Tyka M, Helmes CM, Akhavanpoor M, Rupp G, Domschke $\mathrm{G}$, et al. CXCL4-induced plaque macrophages can be specifically identified by co-expression of MMP7 ${ }^{+} \mathrm{S} 100 \mathrm{~A} 8^{+}$in vitro and in vivo. Innate Immun 2014 March 24, doi:10.1177/1753425914526461.

23. Gleissner CA, Shaked I, Erbel C, Bockler D, Katus HA, Ley K. CXCL4 downregulates the atheroprotective hemoglobin receptor CD163 in human macrophages. Circ Res 2010; 106: 203-211.

24. Kadl A, Meher AK, Sharma PR, Lee MY, Doran AC, Johnstone SR, et al. Identification of a novel macrophage phenotype that develops in response to atherogenic phospholipids via Nrf2. Circ Res 2010; 107: 737-746.

25. Khallou-Laschet J, Varthaman A, Fornasa G, Compain C, Gaston AT, Clement M, et al. Macrophage plasticity in experimental atherosclerosis. PLoS One 2010; 5: e8852, doi:10.1371/journal.pone. 0008852 .

26. Brocheriou I, Maouche S, Durand H, Braunersreuther V, Le Naour $\mathrm{G}$, Gratchev A, et al. Antagonistic regulation of macrophage phenotype by M-CSF and GM-CSF: Implication in atherosclerosis. Atherosclerosis 2010; 214: 316-324.

27. Stoger JL, Gijbels MJ, van der Velden S, Manca M, van der Loos $\mathrm{CM}$, Biessen EA, et al. Distribution of macrophage polarization markers in human atherosclerosis. Atherosclerosis 2012; 225: 461-468.

28. Cho KY, Miyoshi H, Kuroda S, Yasuda H, Kamiyama K, Nakagawara $\mathrm{J}$, et al. The phenotype of infiltrating macrophages influences arteriosclerotic plaque vulnerability in the carotid artery. J Stroke Cerebrovasc Dis 2013; 22: 910-918.

29. Bartel DP. MicroRNAs: Target recognition and regulatory functions. Cell 2009; 136: $215-233$.

30. Chendrimada TP, Gregory RI, Kumaraswamy E, Norman J, Cooch N, Nishikura K, et al. TRBP recruits the Dicer complex to Ago2 for microRNA processing and gene silencing. Nature 2005; 436: $740-$ 744.

31. Valencia-Sanchez MA, Liu J, Hannon GJ, Parker R. Control of translation and mRNA degradation by miRNAs and siRNAs. Genes Dev 2006; 20: 515-524.

32. O'Connell RM, Rao DS, Chaudhuri AA, Baltimore D. Physiological and pathological roles for microRNAs in the immune system. Nat Rev Immunol 2010; 10: $111-122$

33. Raitoharju E, Lyytikainen LP, Levula M, Oksala N, Mennander A, Tarkka M, et al. miR-21, miR-210, miR-34a, and miR-146a/b are up-regulated in human atherosclerotic plaques in the Tampere Vascular Study. Atherosclerosis 2011; 219: 211-217.

34. Bidzhekov K, Gan L, Denecke B, Rostalsky A, Hristov M, Koeppel TA, et al. microRNA expression signatures and parallels between monocyte subsets and atherosclerotic plaque in humans. Thromb Haemost 2012; 107: 619-625.

35. Nazari-Jahantigh M, Wei Y, Noels H, Akhtar S, Zhou Z, Koenen RR, et al. MicroRNA-155 promotes atherosclerosis by repressing Bc16 in macrophages. J Clin Invest 2012; 122: 4190-4202.

36. O'Connell RM, Chaudhuri AA, Rao DS, Baltimore D. Inositol phosphatase SHIP1 is a primary target of miR-155. Proc Natl Acad Sci USA 2009; 106: 7113-7118.

37. Donners MM, Wolfs IM, Stoger LJ, Van der Vorst EP, Pottgens CC, Heymans S, et al. Hematopoietic miR155 deficiency enhances atherosclerosis and decreases plaque stability in hyperlipidemic mice. PLoS One 2012; 7: e35877, doi:10.1371/journal.pone.0035877.

38. Cai X, Yin Y, Li N, Zhu D, Zhang J, Zhang CY, et al. Re-polarization of tumor-associated macrophages to pro-inflammatory M1 macrophages by microRNA-155. J Mol Cell Biol 2012; 4: 341-343.

39. Liu G, Friggeri A, Yang Y, Park YJ, Tsuruta Y, Abraham E. miR147 , a microRNA that is induced upon Toll-like receptor stimulation, regulates murine macrophage inflammatory responses. Proc Natl Acad Sci USA 2009; 106: 15819-15824.

40. Sheedy FJ, Palsson-McDermott E, Hennessy EJ, Martin C, O'Leary JJ, Ruan Q, et al. Negative regulation of TLR4 via targeting of the proinflammatory tumor suppressor PDCD4 by the microRNA miR21. Nat Immunol 2010; 11: 141-147.

41. Taganov KD, Boldin MP, Chang KJ, Baltimore D. NF-kappaB-dependent induction of microRNA miR-146, an inhibitor targeted to signaling proteins of innate immune responses. Proc Natl Acad Sci USA 2006; 103: $12481-12486$.

42. Androulidaki A, Iliopoulos D, Arranz A, Doxaki C, Schworer S, Zacharioudaki V, et al. The kinase Aktl controls macrophage response to lipopolysaccharide by regulating microRNAs. Immunity 2009; 31: 220-231

43. Chaudhuri AA, So AY, Sinha N, Gibson WS, Taganov KD, O'Connell RM, et al. MicroRNA-125b potentiates macrophage activation. J Immunol 2011; 187: 5062-5068.

44. Gallardo-Soler A, Gomez-Nieto C, Campo ML, Marathe C, Tontonoz 
$\mathrm{P}$, Castrillo A, et al. Arginase I induction by modified lipoproteins in macrophages: A peroxisome proliferator-activated receptor-gamma/ delta-mediated effect that links lipid metabolism and immunity. Mol Endocrinol 2008; 22: 1394-1402.

45. Bouhlel MA, Brozek J, Derudas B, Zawadzki C, Jude B, Staels B, et al. Unlike PPARgamma, PPARalpha or PPARbeta/delta activation does not promote human monocyte differentiation toward alternative macrophages. Biochem Biophys Res Commun 2009; 386: 459-462.

46. Kang K, Reilly SM, Karabacak V, Gangl MR, Fitzgerald K, Hatano $\mathrm{B}$, et al. Adipocyte-derived Th2 cytokines and myeloid PPARdelta regulate macrophage polarization and insulin sensitivity. Cell Metab 2008; 7: 485-495.

47. Odegaard JI, Ricardo-Gonzalez RR, Red Eagle A, Vats D, Morel $\mathrm{CR}$, Goforth MH, et al. Alternative M2 activation of Kupffer cells by PPARdelta ameliorates obesity-induced insulin resistance. Cell Metab 2008; 7: 496-507.

48. Prieur X, Mok CY, Velagapudi VR, Nunez V, Fuentes L, Montaner $\mathrm{D}$, et al. Differential lipid partitioning between adipocytes and tissue macrophages modulates macrophage lipotoxicity and M2/M1 polarization in obese mice. Diabetes 2011; 60: 797-809.

49. Stienstra R, Duval C, Keshtkar S, van der Laak J, Kersten S, Muller $\mathrm{M}$. Peroxisome proliferator-activated receptor gamma activation promotes infiltration of alternatively activated macrophages into adipose tissue. J Biol Chem 2008; 283: 22620-22627.

50. Liao X, Sharma N, Kapadia F, Zhou G, Lu Y, Hong H, et al. Kruppellike factor 4 regulates macrophage polarization. J Clin Invest 2011; 121: $2736-2749$.

51. Date D, Das R, Narla G, Simon DI, Jain MK, Mahabeleshwar GH. Kruppel-like transcription factor 6 regulates inflammatory macrophage polarization. J Biol Chem 2014; 289: 10318-10329.

52. Pourcet B, Feig JE, Vengrenyuk Y, Hobbs AJ, Kepka-Lenhart D, Garabedian MJ, et al. LXRalpha regulates macrophage arginase 1 through PU.1 and interferon regulatory factor 8. Circ Res 2011; 109: 492-501.

53. Ma H, Zhong W, Jiang Y, Fontaine $\mathrm{C}$, Li S, Fu J, et al. Increased atherosclerotic lesions in LDL receptor deficient mice with hematopoietic nuclear receptor Rev-erb $\alpha$ knock- down. J Am Heart Assoc 2013; 2: e000235, doi:10.1161/JAHA.113.000235.

54. Hanna RN, Carlin LM, Hubbeling HG, Nackiewicz D, Green AM, Punt JA, et al. The transcription factor NR4A1 (Nur77) controls bone marrow differentiation and the survival of Ly6C- monocytes. Nat Immunol 2011; 12: 778-785.

55. Hamers AA, Vos M, Rassam F, Marinkovic G, Kurakula K, van Gorp PJ, et al. Bone marrow-specific deficiency of nuclear receptor Nur77 enhances atherosclerosis. Circ Res 2012; 110: 428-438.

56. Hanna RN, Shaked I, Hubbeling HG, Punt JA, Wu R, Herrley E, et al. NR4A1 (Nur77) deletion polarizes macrophages toward an inflammatory phenotype and increases atherosclerosis. Circ Res 2012; 110: $416-427$.

57. Chao LC, Soto E, Hong C, Ito A, Pei L, Chawla A, et al. Bone marrow NR4A expression is not a dominant factor in the development of atherosclerosis or macrophage polarization in mice. J Lipid Res 2013; 54: 806-815.

58. Murphy E. Estrogen signaling and cardiovascular disease. Circ Res; 109: 687-696.

59. Ribas V, Drew BG, Le JA, Soleymani T, Daraei P, Sitz D, et al. Myeloid-specific estrogen receptor alpha deficiency impairs metabolic homeostasis and accelerates atherosclerotic lesion development Proc Natl Acad Sci USA 2011; 108: 16457-16462.

60. Rader DJ. Molecular regulation of HDL metabolism and function: Implications for novel therapies. J Clin Invest 2006; 116: 30903100 .

61. Cockerill GW, Rye KA, Gamble JR, Vadas MA, Barter PJ. Highdensity lipoproteins inhibit cytokine-induced expression of endothelial cell adhesion molecules. Arterioscler Thromb Vasc Biol 1995; 15: $1987-1994$.

62. Feig JE, Rong JX, Shamir R, Sanson M, Vengrenyuk Y, Liu J, et al. HDL promotes rapid atherosclerosis regression in mice and alters inflammatory properties of plaque monocyte-derived cells. Proc Natl Acad Sci USA 2011; 108: 7166-7171.

63. Sanson M, Distel E, Fisher EA. HDL induces the expression of the M2 macrophage markers arginase 1 and Fizz-1 in a STAT6-depen- dent process. PLoS One 2013; 8: e74676, doi:10.1371/journal.pone. 0074676.

64. Colin S, Fanchon M, Belloy L, Bochem AE, Copin C, Derudas B, et al. HDL does not influence the polarization of human monocytes toward an alternative phenotype. Int J Cardiol 2014; 172: 179-184.

65. Yamawaki H, Haendeler J, Berk BC. Thioredoxin: A key regulator of cardiovascular homeostasis. Circ Res 2003; 93: 1029-1033.

66. Holmgren A, Lu J. Thioredoxin and thioredoxin reductase: Current research with special reference to human disease. Biochem Biophys Res Commun 2010; 396: 120-124.

67. El Hadri K, Mahmood DF, Couchie D, Jguirim-Souissi I, Genze F, Diderot $\mathrm{V}$, et al. Thioredoxin-1 promotes anti-inflammatory macrophages of the M2 phenotype and antagonizes atherosclerosis. Arterioscler Thromb Vasc Biol 2012; 32: 1445-1452.

68. Mahmood DF, Abderrazak A, Couchie D, Lunov O, Diderot V, Syrovets T, et al. Truncated thioredoxin (Trx-80) promotes pro-inflammatory macrophages of the M1 phenotype and enhances atherosclerosis. J Cell Physiol 2013; 228: 1577-1583.

69. Vezina C, Kudelski A, Sehgal SN. Rapamycin (AY-22,989), a new antifungal antibiotic. I: Taxonomy of the producing streptomycete and isolation of the active principle. J Antibiot (Tokyo) 1975; 28: $721-726$.

70. Terada N, Lucas JJ, Szepesi A, Franklin RA, Domenico J, Gelfand EW. Rapamycin blocks cell cycle progression of activated T cells prior to events characteristic of the middle to late G1 phase of the cycle. J Cell Physiol 1993; 154: 7-15.

71. Inoki K, Corradetti MN, Guan KL. Dysregulation of the TSC-mTOR pathway in human disease. Nat Genet 2005; 37: 19-24.

72. Mercalli A, Sordi V, Ponzoni M, Maffi P, De Taddeo F, Gatti G, et al. Rapamycin induces a caspase-independent cell death in human monocytes. Am J Transplant 2006; 6: 1331-1341.

73. Weichhart T, Costantino G, Poglitsch M, Rosner M, Zeyda M, Stuhlmeier KM, et al. The TSC-mTOR signaling pathway regulates the innate inflammatory response. Immunity 2008; 29: 565-577.

74. Mercalli A, Calavita I, Dugnani E, Citro A, Cantarelli E, Nano R, et al. Rapamycin unbalances the polarization of human macrophages to M1. Immunology 2013; 140: 179-190.

75. Byles V, Covarrubias AJ, Ben-Sahra I, Lamming DW, Sabatini DM, Manning BD, et al. The TSC-mTOR pathway regulates macrophage polarization. Nat Commun 2013; 4: 2834.

76. Assaad-Khalil SH, Lachine N, Sidrak M, Amara F, Jacotot B, Fahmy MH. Immuno-metabolic factors in schistosomal hepatic fibrosis modulating atherogenesis. Ann Biol Clin (Paris) 1992; 50: 697-701.

77. Cudejko C, Wouters K, Fuentes L, Hannou SA, Paquet C, Bantubungi $\mathrm{K}$, et al. p16INK4a deficiency promotes IL-4-induced polarization and inhibits proinflammatory signaling in macrophages. Blood 2011; 118: $2556-2566$.

78. Wolfs IM, Stoger JL, Goossens P, Pottgens C, Gijbels MJ, Wijnands E, et al. Reprogramming macrophages to an anti-inflammatory phenotype by helminth antigens reduces murine atherosclerosis. Faseb J 2014; 28: 288-299.

79. Adams MJ, Hardenbergh PH, Constine LS, Lipshultz SE. Radiationassociated cardiovascular disease. Crit Rev Oncol Hematol 2003; 45: $55-75$.

80. Darby SC, Cutter DJ, Boerma M, Constine LS, Fajardo LF, Kodama $\mathrm{K}$, et al. Radiation-related heart disease: Current knowledge and future prospects. Int J Radiat Oncol Biol Phys 2010; 76: 656-665.

81. Hoving S, Heeneman S, Gijbels MJ, te Poele JA, Russell NS, Daemen $\mathrm{MJ}$, et al. Single-dose and fractionated irradiation promote initiation and progression of atherosclerosis and induce an inflammatory plaque phenotype in ApoE(-/-) mice. Int J Radiat Oncol Biol Phys 2008; 71: $848-857$.

82. Stewart FA, Heeneman S, Te Poele J, Kruse J, Russell NS, Gijbels $\mathrm{M}$, et al. Ionizing radiation accelerates the development of atherosclerotic lesions in $\mathrm{ApoE}^{--}$mice and predisposes to an inflammatory plaque phenotype prone to hemorrhage. Am J Pathol 2006; 168: 649-658.

83. Gabriels K, Hoving S, Gijbels MJ, Pol JF, Te Poele JA, Biessen EA, et al. Irradiation of existing atherosclerotic lesions increased inflammation by favoring pro-inflammatory macrophages. Radiother Oncol 2014; 110: $455-460$. 